\title{
Development Application of Composite Indices (CI): An Emerging Method to the Disciplines of Engineering, Economics and Finance
}

\author{
Chandrasekhar Putcha, PhD, Fellow ASCE \\ Professor, Department of Civil and Environmental Engineering \\ California State University, Fullerton \\ Brian W. Sloboda, PhD \\ University of Phoenix, School of Advanced Studies, \\ Center for Management and Entrepreneurship \\ Mohammadreza Khani \\ Graduate Student, Department of Electrical Engineering \\ Western Michigan University
}

doi: 10.19044/esj.2016.v12n28p1 URL:http://dx.doi.org/10.19044/esj.2016.v12n28p1

\begin{abstract}
Interdisciplinary or multidisciplinary research involves the use of a combination of principles from various disciplines: engineering, economics, finance, etc. This particular approach makes a lot of sense; otherwise, all the research will become compartmentalized, and researchers from one discipline will not know what researchers from other disciplines are doing and how those principles can be applied to their own disciplines. One way to create a common base connecting all these disciplines is to use the concept of composite indicators (CI), which is an emerging field of study. The use of composite indices, as part of an emerging method, for research problems in various fields allows for greater understanding of research problems and provides a visionary approach to solve such problems. This paper first states the existing methods for calculation of composite indicators in the literature and then suggests a new method.
\end{abstract}

Keywords: Composite indices, interdisciplinary, multidisciplinary research

\section{Introduction}

Mathematical principles are used in almost every discipline. The goal of interdisciplinary research is to understand the appropriate mathematical principles and apply them to any discipline to answer the research questions. This paper will focus on application of the concept of composite indicators (CI) for each of the following topics: 
1. Optimal occupancy factor (rate) for hotels

2. Development of a new forecasting model in the estimation of Social Security benefits

3. Mathematical analysis of unemployment benefits

Each topic will be discussed in detail in this paper using a new proposed method based on principles of reliability and risk analysis which are used extensively in various disciplines of engineering. These methods of engineering are applied in this research paper to the field of economics. However, before the new method is proposed and applied to the above three important areas of hotel industry, Social Security benefits, and unemployment benefits, the existing method is discussed in the literature review below, so readers of this study have a good understanding of both the existing method in the literature and the proposed method discussed in this paper.

\section{Existing Literature}

Composite indicators (CI) are synthetic indices of individual indicators (often in different units), and these indicators are often developed to assess various policies. These methodologies have evolved to address a wide range of particular decisions or decision-making processes (Baptista, 2014). Large amount of work were carried out on different topics based on Composite Index. Some of these studies include assessment of human development (Andrews, 1989), well-being and quality of life (Cendrero et al. 2003), poverty (Molle and Mollinga, 2003), and risk and vulnerability management (Birkmann 2007). The composite index has been applied extensively to environmental topics namely sustainability, such as the pilot environment performance index (WEF, 2002), eco-indicator 99 (Pre Consultants, 2004), and the life cycle index (Khan et al., 2004).

In fact, composite indicators are an innovative approach to evaluate sustainability which is a broad research category, and it requires the computing of aggregate values that is used in the development of a composite index. Sustainability is a broad category, and it can be applied analytically to specific research areas. For example, Seljak, Krajnc, and Glavic (2004) index of balanced sustainable development for 24 countries in the European Union (EU) and candidates for the EU for the following years: 1990, 1995 and 1998. The developed a method for aggregating a set of indicators into the Index of balanced sustainable development. More specifically, their approach constructs the index from economic, environmental and social sub-indices, equally weighted together to describe total impact on sustainable development of nations. Using the latter approach, Krajnc and Glavic (2005) then applied its model for integrated assessment of sustainable development across companies. This assessment 
of sustainable development is a quantitative comparison with regards to economic, environment and social issues.

Another application of sustainability would be applied to corporate sustainability. Dow Jones sustainability index represents a widely used composite indicator that assesses corporate sustainability. This sustainability index tracks the stock performance of leading companies via three categories: economic, environmental and social criteria. The goal of is to provide benchmarks for investors who wish to integrate sustainability into their portfolios, and provide an approach for those companies who want to adopt sustainable best practices into their organization (DJSI, 2003). Nowadays, many companies recognize quite heavily and strongly monitor the economic, environmental, and social criteria using sustainability indicators, which provide information concerning how the company contributes to sustainable development (Azapagic and Perdan, 2000). More important, these indicators need to translate sustainability issues into quantifiable measures that precisely measure sustainability (Azapagic, 2004).

The development of composite indicators has been used extensively in the economic indicators as developed by OECD (2002). More specifically, this indicator by the OECD combined consumption level index, human resources development index, composite basic needs indices, composite leading indicators. The OECD CI groups economic statistics by country in order to track and forecast business cycles. Consequently, this type of CI can be subject to empirical tests to assess how well its forecasts are matched to reality. In another index, the index of economic freedom as developed by Johnston and Sheehy (1995) has documented the critical link between economic opportunity and prosperity. Based on this index, it has demonstrated the power of free-market, limited-government, rules-based capitalism with the objective to help people prosper economically.

The usefulness of the composite indicator depends heavily on how the CI incorporates the weighting and aggregation schemes. Thus, the development of the CI in regards to the underlying weighting and aggregation schemes is quite controversial and care must be taken when developing the CI (Esty et al., 2006). The applicability of multiple criteria decision analysis (MCDA) methods has been widely used when aggregating the data for the CI. Once the data are aggregated in the development of the CI, the weights need to be determined. A major problem in applying MCDA aggregation methods to construct a CI is the determination of the weights for the underlying sub-indicators that are used in the development of the CI (Munda and Nardo (2003), Diaz-Balteiro and Romero (2004), and Zhou et al. (2006)). The field of operational research has enabled us to have a valuable tool called data envelopment analysis (DEA) which can be used to derive objective weights for use in the development of the CI. DEA is a 
nonparametric method to evaluate the relative efficiencies of a set of comparable entities using linear programming Charnes et al. (1978). In DEA, each entity selects a set of weights which are most favorable for itself to give a standardized efficiency score (between zero and one). There are two approaches in the use of the DEA when developing the CI. First, the traditional approach identifies inputs and outputs and then constructing the CI using the DEA methods (Färe et al, 2004) while the second approach entails the transformation of all the sub-indicators into the same type of variables (benefit or cost type) and then aggregated into a CI applying the DEA approach (Despotis, 2005).

In brief, CIs are a widely accepted tool for performance monitoring, benchmarking, policy analysis, and public communication with the disciplines of economics, engineering and other disciplines. Despite its popularity, care must be exercised when aggregating the data and then applying a weighting scheme to disseminate the CI. Consequently, care must be exercised when developing a CI so meaningful results are obtained, and these results are not subject to intense scrutiny.

\section{New Proposed Method}

Principles of reliability are extensively used in various fields including engineering, finance, economics and social industries. In here, they will be applied to fields of economics and finance.

Reliability is defined as probability of survival of a system. A system is composed of many components. A proper functioning of a system depends entirely on the proper functioning of the components. Proper functioning of any component implies the ability of the survival of the component. In other words, if a component is subjected to a certain load, one would like to know the probability of survival (i.e., the reliability, R) of the component. Once the component reliability is known, one can calculate the reliability $R_{s}$ of the system. The mathematical expression of the $\mathrm{R}_{\mathrm{s}}$ of the system will depend on how the components are connected. There are mainly two types of ideal systems. One is called the series system, and the other is called the parallel system. In a series system, all the units of the system are supposed to function properly for the system to be reliable. The reliability of a parallel system is expressed as the product of the reliabilities of individual components. On the other hand, in a parallel system, even if one unit of the system works, the system is supposed to be reliable. The reliability of a parallel system is expressed as one minus the product of the failure probabilities (one minus reliability) of the individual units. In the three problems from three distinct industries that are discussed in this paper, it is fair to assume that these systems constitute a series system which gives conservative results. 
$\mathrm{R}_{\mathrm{s}}$ of a series system is defined as (Ebeling,1985):

$$
\mathrm{R}_{\mathrm{s}}=\mathrm{R}_{1} \cdot \mathrm{R}_{2} \cdot \ldots \cdot \mathrm{R}_{\mathrm{n}}
$$

where $\mathrm{R}_{\mathrm{i}}$ is the reliability of the individual components of the system. Using the logic discussed above, the composite indicator or index of a system $\left(\mathrm{CI}_{\mathrm{s}}\right.$ ) can be expressed as

$$
\mathrm{CI}_{\mathrm{s}}=\mathrm{CI}_{1} \cdot \mathrm{CI}_{2} \cdot \ldots \cdot \mathrm{CI}_{\mathrm{n}}
$$

where $\mathrm{CI}_{\mathrm{s}}$ is the composite indicator of the system, and $\mathrm{CI}_{\mathrm{i}}$ is the composite indicator of the components.

Now, the composite indicators (CI) are calculated for three different and distinct industries -hotel industry, Social Security, and the unemployment benefits system. Composite index (CI) is defined for each of the above three research problems. This depends on the independent and dependent variables assumed with the problem. Then, at the end of this study, CI values are calculated for the above three problems.

The details outlining the application of the new methods are described below:

\section{Optimal Occupancy Factor (rate) for Hotels}

This portion of the work is based on the application of the composite index calculation for hotels. First, principles of probability theory for economic data as related to the hotel industry are applied.

\section{The Methodology in the Development of the Composite Index (CI) for Hotels}

It is well-known that hotels are profit maximizers. Hence, hotels would like to achieve the highest occupancy factor (rate) as possible. Past research studies have used variables such as hotels in operation, room nights available, room nights sold, hotel occupancy rate, hotel room price, actual revenue per room, and hotel total revenues. In this paper, a different approach is used to address the same problem. The new model uses only three independent variables. These variables include the total number of rooms in the hotel, the rooms sold on a particular night, and the actual month sold. The data used have been collected for two hotels. In one hotel, the day data are available for the entire 365 days, while only the average monthly data is available for the second hotel. The data collected are used in two ways. First, the data are used to fit an appropriate probabilistic density function and then calculate the probabilities of various levels of occupancy factors. Second, the data are used to establish a functional relationship between the occupancy factor and the temperature. Finally, the composite index (CI) is calculated based on the method discussed earlier in this paper. 


\section{Fullerton Marriott Hotel at California State University, Fullerton}

Data for Fullerton Marriott Hotel are collected (Putcha et al., 2015a). Probability analysis is used extensively in various fields of engineering. In this research, these engineering analysis principles were applied to examples from economics and finance. To calculate the probability of occupancy rate of the hotel shown in Table 1, a normal distribution of the data is needed. Then, a chi-square $\left(\chi^{2}\right)$ test is used to check the validity of the normal distribution as shown in Table 2.

Table 1: Probability of occupancy rate (OR) for Fullerton Marriott Hotel with mean $(\mu)$ and standard deviation values $(\sigma)$ of $\mu_{\mathrm{OR}}=183.44$ and $\sigma_{\mathrm{OR}}=15.49$

Threshold Value

161.6

181.8
$\mathrm{P}(\mathrm{OR}>$ Threshold Value $)$

0.9207

0.5421

Composite index (CI) for Fullerton Marriott hotel is 0.4991 using equation (2).

Table 2: Fullerton Marriott Hotel at California State University, Fullerton

\begin{tabular}{|c|c|c|c|c|c|c|c|}
\hline $\mathrm{X}_{\mathrm{j}}$ & Frequency & $\begin{array}{l}\text { Cumulative } \\
\text { Frequency }\end{array}$ & $\begin{array}{l}\text { Relative } \\
\text { Frequency } \\
\sim f(X)\end{array}$ & $\begin{array}{l}\Phi\left(\left(X_{j^{-}}\right.\right. \\
\mu) / \sigma)\end{array}$ & $\mathrm{e}_{\mathrm{j}}$ & $\mathrm{bj}$ & $\left(b_{j}-e_{j}\right)^{2} / e_{j}$ \\
\hline $\begin{array}{l}143.03- \\
157.78\end{array}$ & 1 & 1 & 0.08 & $\begin{array}{c}0.0046- \\
0.0488\end{array}$ & 0.5862 & 0.5862 & 0.2921 \\
\hline $\begin{array}{l}157.78- \\
172.53\end{array}$ & 0 & 1 & 0.00 & $\begin{array}{c}0.0488- \\
0.2406\end{array}$ & 2.8867 & 0 & 2.8866 \\
\hline $\begin{array}{l}172.53- \\
187.25\end{array}$ & 6 & 7 & 0.50 & $\begin{array}{c}0.2406- \\
0.5968\end{array}$ & 7.1620 & 6 & 0.18853 \\
\hline $\begin{array}{l}187.25- \\
202.03\end{array}$ & 5 & 12 & 0.42 & $\begin{array}{l}0.5968- \\
0.8847\end{array}$ & 10.616 & 5 & 2.97106 \\
\hline
\end{tabular}

Similarly, occupancy rate (OR) for Willow Tree Lodge Hotel are shown in Table 3.

Table 3: Probability of occupancy rate (OR) for Willow Tree Lodge Hotel with mean $(\mu)$ and standard deviation values $(\sigma)$ of $\mu_{\mathrm{OR}}=40.31$ and $\sigma_{\mathrm{OR}}=9.19$

Threshold Value

48

54
$\mathrm{P}(\mathrm{OR}>$ Threshold Value $)$

0.20135

0.06815

This is based on the data in Table 4. Composite index (CI) for Willow Tree Lodge Hotel is 0.0137 based on equation (2).

\begin{tabular}{|c|c|c|c|c|c|c|}
\hline $\mathrm{X}_{\mathrm{j}}$ & Frequency & $\begin{array}{c}\text { Table 4: Willow } \\
\text { Relative Frequency } \\
\sim f(X)\end{array}$ & $\begin{array}{l}\Phi\left(\left(\mathrm{X}_{\mathrm{j}}-\mu\right) / \sigma\right) \\
\text { (1) }\end{array}$ & $e_{j}$ & bj & $\left(b_{j}-e_{j}\right)^{2} / e_{j}$ \\
\hline $25-28.5$ & 16 & 0.04 & $0.0478-0.0993$ & 18.79 & 16 & 0.4146 \\
\hline 28.5-32 & 64 & 0.18 & 0.099-0.1828 & 30.47 & 62 & 32.59 \\
\hline $32-35.5$ & 61 & 0.17 & $0.1828-0.3002$ & 42.837 & 38 & 0.5463 \\
\hline 35.5-39 & 32 & 0.09 & $0.3002-0.4431$ & 52.17 & 46 & 0.7297 \\
\hline $39-42.5$ & 50 & 0.14 & $0.4431-0.5940$ & 55.055 & 50 & 0.4642 \\
\hline 42.5-46 & 44 & 0.12 & $0.5940-0.7319$ & 50.34 & 44 & 0.7997 \\
\hline $46-49.5$ & 29 & 0.08 & $0.7319-0.8412$ & 39.893 & 36 & 0.3799 \\
\hline 49.5-53 & 34 & 0.09 & $0.8412-0.9162$ & 27.391 & 34 & 1.5944 \\
\hline 53-56.5 & 9 & 0.02 & 0.9162-0.9609 & 16.296 & 13 & 0.666 \\
\hline $56.5-60$ & 26 & 0.07 & $0.9609-0.9839$ & 8.4016 & 26 & 36.8623 \\
\hline
\end{tabular}


The calculations stated in Table 1 and Table 3 shown above use the following procedure:

In this phase, a functional relationship is derived between occupancy rate and the average temperature for that month using the concepts of regression analysis (Chapra \& Canale, 2015). A linear regression is fitted as follows:

$\mathrm{OR}=\mathrm{a}+\mathrm{b}(\mathrm{T})$; (3) in which $\mathrm{OR}$ is Occupancy Rate and $\mathrm{T}$ is temperature

The values of $\mathrm{a}$ and $\mathrm{b}$ are obtained from

$a=\overline{O R}-b(\bar{T})$

Where $\overline{O R}$ and $\bar{T}$ are the mean values of $\mathrm{OR}$ and $\mathrm{T}$

$b=\frac{n \sum O R_{i} T_{i}-\sum O R_{i} \sum T_{i}}{n \sum T_{i}^{2}-\left(\sum T_{i}\right)^{2}}$

$\left(\mathrm{OR}_{\mathrm{i}}, \mathrm{T}_{\mathrm{i}}\right)$ is a set of paired observations, and $\mathrm{n}$ is the number of total observations.

The adequacy of this fit is checked from the correlation coefficient (r) and the standard error of estimate $\left(\mathrm{s}_{\mathrm{OR} / \mathrm{T}}\right)$. The correlation coefficient is given as

$r=\frac{n \sum O R_{i} T_{i}-\left(\sum T_{i}\right)\left(\sum O R_{i}\right)}{\sqrt{\left[n \sum T_{i}^{2}-\left(\sum T_{i}\right)^{2}\right]\left[n \sum O R_{i}{ }^{2}-\left(\sum O R_{i}\right)^{2}\right]}}$

\section{The standard error of the estimate is given as}

$$
\begin{gathered}
S_{O R / T}=\sqrt{\frac{S_{r}}{n-2}} \\
S_{r}=\sum_{i=1}^{n}\left(O R_{i}-a-b T_{i}\right)^{2}
\end{gathered}
$$

The results reported in Tables 2 and 4 above use the following procedure:

1. Collect the data for room occupancy from various from Fullerton Marriott at California State University and Willow Tree Lodge Hotels.

2. Calculate the occupancy rate of rooms.

3. Derive the chosen probability density function from visual observation and check the adequacy for the occupancy rate using a chisquare $\left(\chi^{2}\right)$ test (Ang \& Tang, 2007; Kreyszig, 2011). The steps are stated below:

a. Obtain the minimum and maximum values of the occupancy rate.

b. Divide the room data into an appropriate number of divisions.

c. Obtain the theoretical relative and cumulative frequency. Plot the histogram and density function.

d. Divide the data into an appropriate number of divisions and obtain the number of samples falling in that range. This gives $n_{i}$ values for each range.

e. Calculate the corresponding theoretical frequency for the assumed distribution (based on visual observation) from the standard expressions 
available in literature (Ang \& Tang, 2007; Kreyszig, 2011). This gives $e_{i}$ values for each range.

f. Find the sum of $\frac{\left(n_{i}-e_{i}\right)^{2}}{e_{i}}$ values for each range using the following expression:

$\chi^{2}=\sum_{i} \frac{\left(n_{i}-e_{i}\right)^{2}}{e_{i}}$

where i goes up to $\mathrm{N}$ and where $\mathrm{N}$ represents number of divisions into which the collected room data have been divided.

h. Determine the probability from

$\mathrm{P}\left(\chi^{2} \leq \mathrm{c}\right)=1-\alpha$

where $\alpha$ is the significance level. If the chi square $\left(\chi^{2}\right)$ obtained is less than or equal to c, then the chosen distribution from the visual observation is correct. c represents the value of the appropriate $\chi^{2}$ distribution at the cumulative probability.

\section{Development of a new forecasting model in the estimation of Social Security benefits}

This example developed a new way in which Social Security benefits are estimated in response to the reforms to Social Security to retain its financial solvency. Then, suggestions are provided to improve the Social Security model. The present formula for calculation of Social Security benefits, while based on a person's lifetime earnings, uses adjusted or "Indexed" earnings to account for changes in average wages since the earnings were recovered. The indexed earnings, which are more than actual earnings, are used to calculate the actual Social Security benefits. This index factor varies widely in a period of 60 years - from 14.12 in 1953 to 1.0 in 2013. Interestingly, the federal government reduced the index factor to 1.0 in 2012. Therefore, the indexed earnings will be same as actual earnings for future Social Security calculations, resulting in possible reductions in future Social Security benefits. Hence, an attempt is made in the present research to study the current formula for calculation of Social Security benefits in detail, suggest appropriate changes, and propose an improved model that realistically estimates Social Security benefits. To start, a functional relationship in the form of a specific model will be fitted between the index factor and the cumulative number of years. As a result, a new model will be derived. All of these options will be examined, and the best model will be fitted given the data. Finally, a composite index (CI) for the Social Security benefits is calculated. 


\section{Social Security Benefits Model}

Social Security benefits are an important factor to be considered for a person planning to retire. It is mainly based on a factor called Primary Insurance Amount (PIA). This also accounts for the composite index (CI) for the Social Security model.

\section{Illustrative Example (Putcha et al., 2015b)}

Assume a 62 year old man was born in 1950, and his total indexed earnings over his 35 highest-earning years were $\$ 2$ million. This gives an AIME (average indexed monthly earnings) of $\$ 4,762$. The PIA for this person is $\$ 1,945.24$.

The procedure for calculating the Primary Insurance Amount (PIA) is 1. Divide the AIME into three segments. These are called bend points (which are adjusted each year after inflation). There are three bend points. Together, these three bend points give what is known as the primary insurance amount (PIA). $\quad$ Table 1 (http://www.socialsecurity.gov/OACT/COLA/bendpoints.html ) gives the bend points for each year. For 2014 , the first bend point $\mathrm{BP}_{1}$ is $\$ 816$, and the second bend point $\mathrm{BP}_{2}$ is $\$ 4917$.

2. The first bend point of AIME is multiplied by a weightage factor of 0.9 .

3. The difference between first bend point and second bend point of AIME is multiplied by a weightage factor of 0.32 .

4. The difference between the actual AIME and the second bend point (which is essentially the third bend point $\mathrm{BP}_{3}$ ) is multiplied by a weightage factor of 0.15 .

5. The sum of all the three amounts (all from AIME) gives the primary insurance amount (PIA) of the worker.

6. This is the exact amount of Social Security benefits for a person retiring at the age of 66. In the case of the person retiring exactly at 62, the benefits will be 25\% less than the person's primary insurance amount (PIA).

Example 1: Assume a 62 year old person was born 1950, and his total indexed earnings over his 35 highest-earning years were \$2 million. This gives AIME of \$4,762. The PIA for this individual is

\$1,945.24 (http://www.bankrate.com/finance/retirement/how-socialsecurity-benefits-are- calculated.aspx)

\section{Detailed Existing Methodology ${ }^{1}$}

The current methodology to calculate benefits by Social Security is shown below. 
Step

Calculation in the Step

Step 1

Step 2

Step 3

Step 4

Step 5
Computing EMR66=PIA

Description of the Variables used in the Calculation

Obtaining $\mathrm{AE}_{\mathrm{i}}$ (Actual Earning in the $\mathrm{i}$ year) Calculating $\mathrm{IE}_{\mathrm{i}}=\mathrm{AE}_{\mathrm{i}}^{*} \mathrm{IF}_{\mathrm{i}}$

$\mathrm{IF}_{\mathrm{i}}$ is the Index Factor in the $\mathrm{i}^{\text {th }}$ year and $\mathrm{IE}_{\mathrm{i}}$ is the Indexed Earning in the $i^{\text {th }}$ year

where MIE is the sum of the $\mathrm{IE}_{\mathrm{i}}{ }^{*}$ or the highest indexed earnings.

AIME is the Average Indexed Monthly Earnings which is MIE divided by 420 months. EMR: Estimated Monthly Retirement at age 66 PIA: Primary Insurance Amount

1 The Social Security document (www.socialsecurity.gov) explains the steps to be followed to estimate the Social Security benefits, which are illustrated in this table.

Using the three bend points for the year 2014 as stated in steps 3-5 in the methodology and discussed in Sec. 2.1 earlier, the calculations for PIA are shown below:

$($ EMR66) $1=$ PIA1 $=0.9 * 816=734.4$

$($ EMR66) $2=$ PIA2 =

$0.32 *(4917-816)$

$=1312.32$

(EMR66)3=PIA3 $=0.1$

$5 *$ (AIME-

4917)

$=544.7$

Note that $\mathrm{PIA}_{3}$ or (EMR66)3 uses AIME value of 8548.38 for the example under consideration.

Also, it should be noted that $\mathrm{PIA}_{1}$ and $\mathrm{PIA}_{2}$ are purely dependent on the first and second bend points for the year under consideration (2014 in this example) given in Table 1 , while $\mathrm{PIA}_{3}$ uses AIME and the value of the second bend point.

Hence,

EMR66 $=($ EMR66 $) 1+($ EMR66 $) 2+($ EMR66 $) 3=$ PIA1 + PIA2 + PIA3

This gives a total value of $\mathrm{PIA}_{3}$ or EMR66 as \$2,591.74 using the above expression. An alternate expression for EMR66 has been derived for the earnings of 2014 which is given as:

EMR66=PIA $=0.15^{*}$ AIME +1309.17

It varies from year to year as it uses bend points which also vary from year to year. 
An equation has been developed encompassing all the above steps. The equation is given as

$$
\mathrm{EMR}_{66}=\mathrm{PIA}=0.15 \sum \frac{I E_{i}^{*}}{420}+1309.17
$$

Where

$\mathrm{IE}_{\mathrm{i}}$ : Indexed Earning in the $\mathrm{i}^{\text {th }}$ year

$\mathrm{IE}_{\mathrm{i}}^{*}: \mathrm{IE}_{\mathrm{i}} \mathrm{s}$ which have maximum values

\section{A New Methodology}

More important, the entire calculation of Social Security benefits using the present methodology is based on the primary insurance amount, which is a three-legged stool consisting of essentially three bend points with associated weightage factors of $90 \%, 32 \%$, and $15 \%$. The data for AIME and PIA are shown in Table 5 (Putcha et al., 2015b). The PIA can be considered the composite index (CI) for the Social Security problem.

Table 5: Plot points for PIA (Primary Insurance Amount) and CI (Composite Index Monthly Earnings) for the 2014 cohort.

$\begin{array}{cc}\text { AIME } & \text { CI of Social Security } \\ \$ 0 & \$ 0 \\ \$ 408 & \$ 367 \\ \$ 816 & \$ 734 \\ \$ 2867 & \$ 1391 \\ \$ 4917 & \$ 2047 \\ \$ 5459 & \$ 2128 \\ \$ 6000 & \$ 2209\end{array}$

Table 5 shows the PIA values at discrete points. Hence, it is important to develop a functional relationship between AIME and CI. In this way, if an individual's earnings are not exactly the same as AIME listed in Table 5, one can use the equation developed in this paper to calculate the exact CI instead of executing the tedious calculations. A cubic spline is fitted to determine the best fit, and the results are shown in Table 5. In engineering analysis, both the regular smooth polynomials as well as splines (linear, quadratic and cubic spline) are used based on the practical data.

\section{The Cubic Spline}

If a cubic spline relation is fitted, then the equations are given as follows:

Segment 1:

$$
\mathrm{PIA}=-7.63 \times 10^{-8} * \mathrm{AIME}^{3}+0.95 * \text { AIME }
$$

Segment 2:

$$
\mathrm{PIA}=2.2 \times 10^{-8} \mathrm{AIME}^{3}-2.99 \times 10^{-4} \mathrm{AIME}^{2}+1.48551 \text { AIME-621.562 }
$$


Segment 3:

$$
\mathrm{PIA}=-7.6 \times 10^{-9} \mathrm{AIME}^{3+0.0001368} \mathrm{AIME}^{2}-0.663 \mathrm{AIME}+2903.04
$$

In this case, the correlation coefficient (r) and the standard error of estimate $\left(\mathrm{S}_{\mathrm{y}} / \mathrm{x}\right)$ values are:

$$
\begin{aligned}
& \mathrm{r} 1=0.99 \quad(\mathrm{Sy} / \mathrm{x}) 1=15.42<(\mathrm{Sy}) 1=367 \\
& \mathrm{r} 2=0.7168 \quad(\mathrm{Sy} / \mathrm{x}) 2=647.32<\left(\mathrm{S}_{\mathrm{y}}\right) 2=656.5 \\
& \text { r3 }=0.999 \quad\left(\text { Sy/x) 3=3.99 }<\left(S_{y}\right) 3=81\right.
\end{aligned}
$$

The above results show that the cubic spline is a good fit. Furthermore, the new values for CI and weightage factors are then shown in Table 6.

Table 6: CI and the Weightage Factors

\begin{tabular}{|c|c|c|c|c|c|c|}
\hline & \multicolumn{2}{|c|}{} & \multicolumn{4}{|c|}{ New CI and Weightage Factors } \\
\hline AIME & \multicolumn{2}{|c|}{ CI Existing Linear Curve } & \multicolumn{2}{|c|}{ Cubic Spline } & \multicolumn{2}{c|}{ Cubic Smooth Curve } \\
\hline & CI & Weightage factor & CI & Weightage factor & CI & Weightage \\
\hline$\$ 816$ & $\$ 734$ & 0.899 & $\$ 733.78$ & 0.8992 & $\$ 626.62$ & 0.76791 \\
\hline$\$ 4917$ & $\$ 2047$ & 0.4163 & $\$ 2046.99$ & 0.4163 & $\$ 1975.36$ & 0.40174 \\
\hline$\$ 6000$ & $\$ 2209$ & 0.3681 & $\$ 2208.24$ & 0.3680 & $\$ 2254.7$ & 0.3757 \\
\hline
\end{tabular}

\section{Mathematical Analysis of Unemployment Benefits}

The last part of the paper addresses the development of a mathematical model to calculate unemployment benefits. At a conceptual level, unemployment benefits can be considered directly proportional to salary and the employment period of the worker prior to being laid off. It is also inversely proportional to other factors such as other government benefits received during the period of unemployment. The rudimentary calculation of unemployment is the sum of the two highest quarter gross wages, divided by two, and then multiplied by a percentage to obtain weekly benefits. A simpler formula needs to be derived to calculate unemployment benefits to keep up with the capricious wages and changing regulations. An analysis of federal government benefits as well as state government benefits will be performed to calculate this new formula. Each state should be able to adapt the new formula so that it can assess the proper baseline for calculating the unemployment benefits needed for its specific cost of living requirements. A regression analysis will be performed using the salary and working time along with other benefits received and indexed with unemployment benefits received to arrive at a mathematical model for unemployment benefits. Then, a composite index (CI) is calculated for unemployment benefits. The unemployment benefits are shown in Tables $7-9$ for three states: California, Texas, and New York. In this case, the composite index (CI) is calculated from the average of the weekly data for the whole year (Tabba et al., 2016). 
Based on this concept, a summary of the composite index (CI) values for California, Texas, and New York are summarized in Table 10.

Table 7: Unemployment Benefits for California Date

$1 / 31 / 2011$

2/28/2011

$3 / 31 / 2011$

$4 / 30 / 2011$

5/31/2011

6/30/2011

7/31/2011

8/31/2011

9/30/2011

10/31/2011

$11 / 30 / 2011$

$12 / 31 / 2011$

$1 / 31 / 2012$

2/29/2012

3/31/2012

4/30/2012

$5 / 31 / 2012$

6/30/2012

$7 / 31 / 2012$

8/31/2012

9/30/2012

10/31/2012

$11 / 30 / 2012$

$12 / 31 / 2012$

$1 / 31 / 2013$

2/28/2013

$3 / 31 / 2013$

4/30/2013

5/31/2013

6/30/2013

7/31/2013

8/31/2013

9/30/2013

10/31/2013

$11 / 30 / 2013$

12/31/2013
Average Weekly Benefits

$\$ 292.64$

$\$ 289.76$

$\$ 290.78$

$\$ 290.92$

$\$ 293.31$

$\$ 296.54$

$\$ 294.69$

$\$ 293.55$

$\$ 294.86$

$\$ 294.76$

$\$ 292.98$

$\$ 291.88$

$\$ 293.30$

$\$ 292.21$

$\$ 291.54$

$\$ 291.98$

$\$ 295.25$

$\$ 296.93$

$\$ 296.80$

$\$ 296.82$

$\$ 297.56$

$\$ 296.82$

$\$ 296.32$

$\$ 296.14$

$\$ 298.87$

$\$ 296.19$

$\$ 295.42$

$\$ 296.88$

$\$ 300.95$

$\$ 303.59$

$\$ 303.13$

$\$ 302.67$

$\$ 304.50$

$\$ 304.65$

$\$ 303.16$

$\$ 301.93$

Table 8: Unemployment Benefits for Texas

\section{Date}

1/31/2011

$2 / 28 / 2011$

$3 / 31 / 2011$

$4 / 30 / 2011$

$5 / 31 / 2011$

6/30/2011

$7 / 31 / 2011$

$8 / 31 / 2011$

9/30/2011

$10 / 31 / 2011$

$11 / 30 / 2011$

$12 / 31 / 2011$

$1 / 31 / 2012$
Average Weekly Benefits

$\$ 315.57$

$\$ 316.59$

$\$ 317.05$

$\$ 319.41$

$\$ 319.29$

$\$ 313.64$

$\$ 310.22$

$\$ 310.29$

$\$ 313.85$

$\$ 314.58$

$\$ 316.66$

$\$ 320.75$

$\$ 321.36$ 


$\begin{array}{cc}2 / 29 / 2012 & \\ 3 / 31 / 2012 & \$ 320.88 \\ 4 / 30 / 2012 & \$ 321.90 \\ 5 / 31 / 2012 & \$ 326.01 \\ 6 / 30 / 2012 & \$ 326.18 \\ 7 / 31 / 2012 & \$ 323.65 \\ 8 / 31 / 2012 & \$ 322.46 \\ 9 / 30 / 2012 & \$ 321.55 \\ 10 / 31 / 2012 & \$ 327.64 \\ 11 / 30 / 2012 & \$ 328.32 \\ 12 / 31 / 2012 & \$ 330.53 \\ 1 / 31 / 2013 & \$ 336.43 \\ 2 / 28 / 2013 & \$ 337.20 \\ 3 / 31 / 2013 & \$ 336.78 \\ 4 / 30 / 2013 & \$ 338.11 \\ 5 / 31 / 2013 & \$ 342.00 \\ 6 / 30 / 2013 & \$ 341.05 \\ 7 / 31 / 2013 & \$ 338.68 \\ 8 / 31 / 2013 & \$ 335.75 \\ 9 / 30 / 2013 & \$ 336.56 \\ 10 / 31 / 2013 & \$ 344.11 \\ 11 / 30 / 2013 & \$ 345.10 \\ 12 / 31 / 2013 & \$ 348.33 \\ & \$ 353.10\end{array}$

Table 9: Unemployment Benefits for New York Date $1 / 31 / 2011$

$2 / 28 / 2011$

$3 / 31 / 2011$

$4 / 30 / 2011$

$5 / 31 / 2011$

$6 / 30 / 2011$

$7 / 31 / 2011$

$8 / 31 / 2011$

9/30/2011

$10 / 31 / 2011$

$11 / 30 / 2011$

$12 / 31 / 2011$

$1 / 31 / 2012$

$2 / 29 / 2012$

$3 / 31 / 2012$

$4 / 30 / 2012$

$5 / 31 / 2012$

$6 / 30 / 2012$

7/31/2012

$8 / 31 / 2012$

9/30/2012

$10 / 31 / 2012$

$11 / 30 / 2012$

$12 / 31 / 2012$

$1 / 31 / 2013$

$2 / 28 / 2013$

$3 / 31 / 2013$

$4 / 30 / 2013$

$5 / 31 / 2013$

6/30/2013
Average Weekly Benefits

$\$ 302.91$

$\$ 305.03$

$\$ 304.34$

$\$ 303.36$

$\$ 304.26$

$\$ 304.06$

$\$ 298.49$

$\$ 297.42$

$\$ 301.36$

$\$ 301.01$

$\$ 302.48$

$\$ 302.91$

$\$ 304.01$

$\$ 305.57$

$\$ 305.11$

$\$ 304.57$

$\$ 308.53$

$\$ 305.91$

$\$ 302.78$

$\$ 301.54$

$\$ 305.24$

$\$ 306.49$

$\$ 304.75$

$\$ 303.34$

$\$ 307.07$

$\$ 307.62$

$\$ 307.88$

$\$ 307.94$

$\$ 311.39$

$\$ 310.07$ 
$7 / 31 / 2013$

$8 / 31 / 2013$

$9 / 30 / 2013$

$10 / 31 / 2013$

$11 / 30 / 2013$

$12 / 31 / 2013$
$\$ 304.91$

$\$ 304.27$

$\$ 308.28$

$\$ 312.18$

$\$ 309.28$

$\$ 309.74$

Table 10: Composite Indices (CI) for California, Texas, and New York

State

California

Texas

New York
Composite Index (CI)

296.396

328

305

\section{Conclusion}

In this paper, a new definition of composite index (CI), as part of an emerging method, is defined based on the basic concept of reliability, which is predominantly used in engineering. It is then applied to topics in economics and finance, especially to the hotel industry, the determination of Social Security benefits, and unemployment benefits. Thus, the versatility of the use of composite index has been demonstrated through practical examples. Since all this comes under general area of emerging method, the study and the results reported herein are of even more practical importance. In future research, it is very important that the concept of CI is nondimensionalized, so it can be used on a uniform basis. For this application in the area of emerging method, additional research is required.

\section{References:}

1. Andrews, F. M. (1989). The Evolution of a Movement. Journal of Public Policy, 9(4), 401-405.

2. Azapagic, A., (2004). Developing a Framework for Sustainable Development Indicators for the Mining and Minerals Industry. Journal of Cleaner Production, 12, 639 - 662.

3. Azapagic, A., Perdan, S., (2000). Indicators of Sustainable Development for Industry: A General Framework. Trans. IChemE Process Safety and Environmental Protection Part B, 78 (B4), 243 261.

4. Baptista, S. R. (2014). Design and use of composite indices in assessments of climate change vulnerability and resilience.

5. Birkmann, J. (2007). Risk and vulnerability indicators at different scales: Applicability, usefulness, and policy implications. Environmental Hazards, 7(1), 20-31.

6. Cendrero, A., Francés, E., Del Corral, D., Fermán, J. L., Fischer, D., Del Río, L., Camino, M., and López, A. (2003). Indicators and indices of environmental quality for sustainability assessment in 
coastal areas: Application to case studies in Europe and the Americas. Journal of Coastal Research, 19(4), 919-933.

7. Charnes, A., Cooper, W.W., and Rhodes, E., (1978). Measuring the Efficiency of Decision Making Units. European Journal of Operational Research 2, 429-444.

8. Despotis, D.K., (2005). A Reassessment of the Human Development Index via Data Envelopment Analysis. Journal of the Operational Research Society 56, 969-980.

9. Diaz-Balteiro, L. and Romero, C., (2004). In Search of a Natural Systems Sustainability Index. Ecological Economics 49, 401-405.

10. DJSI-Dow Jones Sustainability Indexes, 2003. (2004). Corporate sustainability sector Overview-DJSI Industry Group Oil, Gas and Coal Companies. Accessed on March 1, 2016 at http://www.sustainability-index.- com .

11. Ebeling, C. (1985). Reliability and Maintainability Engineering. McGraw-Hill.

12. Esty, D.C., Levy, M.A., Srebotnjak, T., de Sherbinin, A., Kim, C.H., and Anderson, B. (2006). Pilot Environmental Performance Index. Yale Center for Environmental Law \& Policy, New Haven.

13. Färe, R., Grosskopf, S., and Hernández-Sancho, F., (2004). Environmental Performance: An Index Number Approach. Resource and Energy Economics 26, 343-352.

14. Johnston, B.T., Sheehy, T.P., (1995). The Index of Economic Freedom. Heritage Foundation, Washington, pp. ix-21

15. Khan, F., Sadiq, R., and Veitch, B., (2004). Life Cycle iNdeX (LInX): a new indexing procedure for process and product design and decision-making. Journal of Cleaner Production. 12, 59-76.

16. Krajnc, D., and Glavic, P. (2005). A Model for Integrated Assessment of Sustainable Development. Resources. Construction, Recycling. 43, 189-208.

17. Molle, F., and Mollinga, P. (2003). Water poverty indicators: Conceptual problems and policy issues. Water Policy, 5, 529-544.

18. Munda, G. and Nardo, M., (2003). On the Methodological Foundations of Composite Indicators Used for Ranking Countries. Proceeding of the First OECD/JRC Workshop on Composite Indicators of Country performance. JRC, Ispra

19. OECD_-Organisation for Economic Co-operation and Development (2002). An Update of the OECD Composite Leading Indicators. Short-term economic Statistics division, Statistics Directorate/OECD. Accessed on February 28, 2016 at http://www.oecd.org. 
20. Pre Consultants, 2004. The Eco-indicator 99-A Damage Oriented Method for Life Cycle Assessment. Methodology Report, Accessed on March 1, 2016 at : http://www.pre.nl/.

21. Putcha, C., Sloboda, B., Putcha, V., Khani, M., \& Tabba, A. (2015a). Financial Aspects of Determining Optimal Occupancy Factor for Hotels Based on Probabilistic Analysis. Global Conference on Business and Finance Proceedings (GCBF). Vol. 10, No. 1. (pp. 3946), ISSN 1941-9589, Las Vegas, Nevada.

22. Putcha, C., Sloboda, B., \& Khani, M., (2015b). A New Approach for a Forecasting Model in the Estimation of Social Security Benefits. The $35^{\text {th }}$ International Symposium on Forecasting, ISF 2015 Proceedings, Riverside, California.

23. Seljak, J., Krajnc, D., and Glavic, P. (2004). Measuring Sustainability --- Index of Balanced Sustainable Development, in Subhas Sikdar, Peter Glavic, and Ravi Jain (eds), Technological Choices for Sustainability, Springer Berlin Heidelberg, 335-353.

24. Tabba, A., Putcha, C, Sloboda, B., Khani, M., and Penumurty, V. (2016). Mathematical Analysis of Unemployment Benefits. Proceedings of Global Conference on Business and Finance (GCBF). Honolulu, January 4-7, 2016.

25. World Economic Forum (WEF) (2002). An initiative of the Global Leaders of Tomorrow Environment Task Force. Annual Meeting 2002. Pilot Environment Performance Index. Accessed on March 1, 2016 at http:// www.ciesin.columbia.edu/indicators/ESI/EPI2002_11- FEB02.pdf.

26. Zhou, P., Ang, B.W., and Poh, K.L., (2006). Comparing Aggregating Methods for Constructing the Composite Environmental Index: An Objective Measure. Ecological Economics 59, 305-311. 